\title{
Ethics and Values in the Digital Environment: by the Example of Parody Videos on TikTok
}

\section{Irina P. Busurkina}

Institute of Sociology RAS, Research Center for Cultural Exclusion and Frontier Zones (RCCEFZ RAS). Saint Petersburg, Russia. Email: ipbusurkina[at]gmail.com

\begin{abstract}
The ethics of the comic is a relatively new interdisciplinary field of knowledge that is gaining new relevance with the development of a variety of social media. The purpose of this article is to review the existing research and show by examples how ethics and values are closely related to the specific functions of social media, such as distributing parody content and commenting on it. The main focus of our study is a parody which can be defined as communicative behavior in the form of a text, movement, or even a song, imitating the characteristics or behavior of the object being ridiculed. Unlike a literal quotation, a parody reproduces the original in a distorted form for the purpose of mockery. Within this article modern ethical approaches to the evaluation of parody as well as the main functions of parody in the digital environment are considered. Based on the examples of parody videos on TikTok the particular ways of expressing social problems and cultural traumas by using the comic strategies are identified. Furthermore, the issues of algorithmic censorship concerning such videos as well as the problem of the moral autonomy of users are discussed.
\end{abstract}

Keywords

Ethics of Parody; Ethical Expertise; Parody Videos, Digital Media; Values of Humor; Informational Services; TikTok; Humor Censorship; Humor as Social Criticism; Cultural Trauma 


\section{Этика и ценности в цифровом пространстве: на примере пародийных видео в TikTok}

\section{Бусуркина Ирина Петровна}

Социологический институт РАН, Центр изучения зон культурного отчуждения и пограничья (ЦИЗКОП СИ РАН). Санкт-Петербург, Россия. Email: ipbusurkina[at]gmail.com

\section{Аннотация}

Этика комического является относительно новой междисциплинарной областью знания, приобретающей актуальность с развитием множества социальных медиа. Цель нашей статьи рассмотреть существующие исследования и показать на примерах, насколько тесно этика и ценности связаны с конкретными функциями социальных медиа, такими как распространение контента пародийного содержания и его комментирование. Основной фокус нашей работы пародия, которую можно определить как коммуникативное поведение в форме текста, движений и даже песни, имитирующее характерные черты или действия высмеиваемого объекта. В отличие от дословной цитаты, пародия воспроизводит оригинал в переработанном виде с целью создания у зрителя или читателя комического эффекта. В статье мы рассматриваем современные этические подходы к оценке пародии, приводим основные функции пародии в цифровом пространстве, а затем на примере пародийных видеороликов в TikTok показываем способы выражения социальных проблем и культурных травм через комические стратегии. Кроме этого, обсуждаются вопросы алгоритмической цензуры в отношении подобных видеороликов, а также проблема моральной автономии пользователей.

\section{Ключевые слова}

этика пародии; этическая экспертиза; пародийные видео; цифровые медиа; ценности юмора; тнформационные сервисы; TikTok; цензура юмора; юмор как социальная критика; культурная травма

Это произведение доступно по лицензии Creative Commons «Attribution» («Атрибуция») 4.0 Всемирная 


\section{Введение}

Этика в цифровую эпоху, точно так же как и в предшествующие, требует расширенного понимания человеческих мотивов, принимаемых на их основе решений, а также исследований последствий поступков. Опосредованные цифровыми возможностями, этика и ценности тесно связаны с конкретными реакциями пользователей на те или иные всплески обсуждений в социальных медиа. Это послужило поводом для зарождения отдельного направления этической инженерии, целью которого является обнаружение и решение этических проблем, связанных с использованием технологий (Sullivan \& Reiner, 2020).

Ключевым моментом в развитии этичного отношения между людьми в условиях цифровой среды является обеспечение автономии пользователя, то есть возможности рефлексировать над своими действиями в сети, определять свои ценности в отношении потребляемого и производимого контента, а также встречаться с последствиями своих поступков. В данной статье обсуждаются вопросы этического осмысления производства и распространения пародийного контента, который переживает новый пик популярности в сети Интернет благодаря всемирно известным сервисам, таким как TikTok и YouTube.

Пародия за счет своих средств выразительности может в развлекательной форме побудить общественность к дискуссии. В статье приводятся примеры того, как пародия используется в качестве тактики против притеснения, призыва к акциям и даже средства распространения исторических сюжетов. Пародию активно задействуют для поднятия острых социальных и политических вопросов. Благодаря тому, что пародия всегда имеет оригинал, доступный для полного понимания лишь членам сегмента общества, ее роль в формировании идентичности с какой-либо социальной группой и культурным прошлым еще предстоит изучить.

Пародия позволяет поддерживать определенные политические настроения, подпитывая критическую культуру общественности через комическое изображение объекта насмешки (Hariman, 2008). Однако восприятие комического контента сильно селективно - оно варьируется от отношения к проблеме и культурного уровня зрителя. Те, кто являются ценителями подобного жанра, могут использовать пародию для повышения осведомленности об общественных настроениях или для развлечения, остальные же вряд ли будут убеждены заложенными в нее идеями, а возможно даже окажутся настроенными негативно. Пародия позволяет ее создателю поделиться своим видением проблемы и идеями, обнажающими существующие ограничения. Таким образом, пародия служит индикатором общественных ценностей и противоречий, являясь ценным источником информации для исследователей в области этики и конфликтологии. 
В данной статье мы рассматриваем современные этические подходы к оценке пародии, приводим некоторые типы и выразительные средства пародии в цифровом пространстве, а затем на примере пародийных видеороликов в TikTok показываем способы выражения социальных проблем и потрясений через комические стратегии. Кроме этого, мы обсуждаем вопросы алгоритмической цензуры в отношении подобного контента, а также затрагиваем проблему моральной автономии пользователей социальных сервисов.

\section{Подходы к этическому осмыслению пародии}

Различные формы комического, в том числе и пародия - это неотъемлемая часть жизни, в которой дают о себе знать культурные, расовые, гендерные и социальные различия. Они имеют собственные дискурсивные характеристики, зависящие от времени и места воспроизведения. Пародия может нести не только комический смысл, она интересна с философской и этической точки зрения, ее анализ важен и часто недооценен.

Хотя этика пародии - это относительно новая междисциплинарная область знания, в ней уже достигнут относительный консенсус. Основная сложность в том, что границы этических норм комического являются крайне расплывчатыми. Поэтому в научной литературе много внимания уделяется его способности причинять вред, так как это оказывается наиболее очевидным маркером границы между этичными и неэтичными высказываниями. Вопрос осложняется тем, что данные высказывания могут быть неподобающими как по отношению к изображаемому объекту, так и по отношению к зрителям. Например, пародия может маскировать негативные сообщения и транслировать расистские и гендерные стереотипы, тем самым закрепляя их в обществе еще больше (Benatar, 1999).

На данный момент существуют несколько взаимосвязанных подходов к этической критике комического, к которому мы относим пародию (Smuts, 2010). При оценке комических высказываний редко применяется теория установочного одобрения; чтобы оценить мотивы, стоящие за ироничным изображением объектов, современными исследователями используются теории заслуженной реакции, эмоциональной ответственности. Основным фокусом утилитарной теории является ситуативность - приносит ли комическое высказывание больше пользы или вреда в конкретной ситуации. Например, в работе Р. Тепли ставится вопрос, способствует ли юмор улучшению повседневных взаимодействий между людьми (Тapley, 2007). Теория несовместимости гласит, что любая ситуация делается комической, если она неуместна, а значит само несоответствие между реальностью и абсурдом становится главным развлечением.

Объёмная доля разысканий касается области политической пародии на сегодняшний день это одно из самых быстро развивающихся направлений в изучении медийной культуры. В эссе исследователя медиа Дж. Пайфера 
рассматриваются обязательства и ограничения, которые налагаются на пародию, в особенности на шутки политического характера (Peifer, 2012). Оценка комического также находится в центре внимания в статье «Юмор как социальный акт: этические проблемы» Дж. Харви (Harvey, 1995). Исследовательница утверждает, что любое комическое высказывание является социальным актом, который совершается в группах людей со смешанным общественным статусом. Они могут усиливать различия во властных отношениях в пользу людей с высоким положением. Поэтому по-настоящему наслаждаться чувством юмора могут только люди, у которых есть статус и власть.

Таким образом, комические высказывания могут служить инструментом воздействия на социальные, политические и этические взгляды других людей. Это обусловлено тем, что они сами по себе отражают широкий социальный и политический контекст, могут поддерживать и даже менять существующий порядок. Их восприятие зависит от отношений между нарратором и зрителем, от его текущих воззрений. Согласно Х. ЛаФоллету и Н. Шанксу, при этом взаимодействии важную роль играет то, какие модели убеждений задействуются (LaFollette \& Shanks, 1993). То, что находится в пограничье между различными взглядами, всегда является источником конфликтов. Именно шаблоны определяют, что видится комическим в явлениях, событиях или людях, которые становятся предметом пародии.

Модели убеждений - неотъемлемая часть этих контекстов, их нелегко отделить от общества и культуры. Поэтому средства пародии часто используются для того, чтобы повлиять на мнение людей об определенном событии или социальной группе. Это может быть преувеличенное представление отрицательных черт, которое укрепляет существующие стереотипы. В подобном ключе оскорбительные характеристики являются отражением доминирующих взглядов и отношения к целевой группе. За пределами таких границ пародия перестает быть художественным примером или формой социальной критики.

Некоторые исследователи ставят вопрос об этических нормах под другим углом (Shuster, 2013). Они рассуждают, не делает ли пародию более комической именно ее неоднозначное содержание. М. Шустер, по-новому истолковывая философию юмора А. Бергсона, делает вывод о том, что именно из-за оскорбительного смысла пародия становится смешнее. В этом случае пародия позволяет реабилитировать и легитимизировать оскорбление, представляя его в театрализованном виде (Lockyer \& Pickering, 2005).

\section{Пародия в цифровом пространстве как форма общественного участия}

В научном дискурсе пародия определяется как коммуникативное поведение в форме текста, движений и даже песни, которое имитирует характерные черты или действия высмеиваемого объекта (Palmer, 2005). В отличие от дословной цитаты, пародия воспроизводит их в переработанной, театрали- 
зованной манере с целью создания у зрителя или читателя комического эффекта.

В современной научной литературе наибольшее внимание уделено воздействию пародии на общественные настроения в медиа. Многие из этих работ показывают, как пародийные ролики могут служить в качестве призыва к действию, например - к участию в политической активности. Пародия и связанные с ней формы комического являются одними из лучших средств выражения отчуждения от доминирующих нормативных ценностей общества. Комическое повествование становится особенно подходящим для выражения оппозиционной или политической позиции. Это достигается за счет того, что пародия трансформирует ценности в образы, доступные для аудитории (Hariman, 2008). В статье Лима и Голана с помощью экспериментов была доказана высокая сила убедительности видео пародии на YouTube, а также ee влияние на вероятность политического участия в социальных сетях (Lim \& Golan, 2011).

В зависимости от объекта различают пародию, используемую политиками, и пародию, созданную не-политиками о политических деятелях. В первом случае уменьшается острота общественной критики, чтобы переключить внимание аудитории с обоснованных опасений касательно создавшейся ситуации. Во втором - пародия вскрывает существующие проблемы (Morreall, 2005). Она рассматривается как инструмент транслирования политических суждений, поскольку ее убедительная сила состоит в так называемом «эффекте шутки» (Nabi et al., 2007): пародия привлекательна тем, что способна вызвать как положительные эмоции, так и «горький смех».

Некоторые исследования направлены на раскрытие роли негативных эмоций и моральных последствий, вызванных пародией. Проводимое различие между «поверхностной» и «глубокой» пародией подразумевает, что первая просто имитирует поведение субъекта, а вторая - наделяет объект насмешки новыми смыслами (D’Errico \& Poggi, 2016). Оба типа пародии влияют на процессы убеждения, но глубокая пародия, в отличие от поверхностной, вызывает больше негативных эмоций. Это приводит к более критическим оценкам объекта и недовольству его моральным обликом.

Из-за популярности пародии в интернете многие работы направлены на то, чтобы получить представление об ее выразительных средствах и механизмах, с помощью которых юмористический контент достигает своего эффекта (Hoffman \& Young, 2011). При помощи эмпирических данных выделяются и сравниваются различные типы пародии, анализируется ее содержательное наполнение и выявляется склонность людей к определенному типу юмора (Holbert, 2015). Значительное количество ученых стараются определить особенности восприятия комедии зрителями, а также спрогнозировать потребление пародийного контента (Hmielowski et al., 2011).

Современные формы пародии и политического юмора разделяют на три категории: карнавализация (политической и общественной) жизни, пародийная 
переработка дискурсов, а также протестная деятельность и активизм (Petrović, 2018). Пародии всегда присуща двусмысленность, которая призывает зрителя к рефлексии высмеиваемых явлений - это позволяет ему сформировать собственное отношение к объекту. А. Пиата предлагает прослеживать связь между метафорой и юмором, которые, согласно его исследованию, служат конкретным риторическим целям: метафора - оценочной рамкой, а юмор средством критики (Piata, 2016).

По типу влияния на зрителей выделяется несколько видов юмористических высказываний: навешивание ярлыков и фреймирование (Guo, 2018). Эти тенденции связаны с переходом онлайн-среды к дискурсивным жанрам игре, пародии и карнавалу. Интернет-культура породила новые способы и формы комментирования политических вопросов. Активное развитие пародии в Интернете может свидетельствовать о том, что функцией онлайн-общения становится в том числе социальная критика, которая отражает идеологические сдвиги в обществе.

Меньше всего внимания в научной литературе уделялось изучению более эгалитарных форм политического и развлекательного контента комического характера. Современные социальные сети позволяют пародийным роликам распространяться быстрее, обходить цензуру и вызывать обширную реакцию людей. В отличие от традиционных телевизионных шоу или пародийных скетчей в журналах, которые создают профессиональные комики, социальные сети и стриминговые платформы предоставляют возможность производить пользовательскую пародию и вирусный визуальный контент - форматы, которые стали играть все более важную роль в новой медиа-среде (Becker \& Waisanen, 2013). Хотя роль интернет-пародии, конечно, не ограничивается только социальным комментированием, иногда такие ролики становятся предметом общественных дискуссий (Ruliou, 2015).

В статье M. Джонса (Jones, 2017) приводится пример того, как политическая пародия в социальных сетях может служить средством для экспериментирования, создания жанров, ранее маргинализированных или не одобряемых официальной государственной властью. На примере культурного производства в Бахрейне исследователь показывает, насколько важную роль играют социальные сети в формировании и определении творческого сопротивления. Мемы и пародийные ролики на YouTube становятся отражением оппозиционного контрнарратива. Таким образом, социальные сети способствуют появлению новых форм пародии, позволяют активистам показать целостность оппозиционной эстетики как местной, так и международной аудитории.

Похожее исследование деятельности творческих активистов показывает, что использование стендап-комедии и публичных образов может подрывать легитимность оппонентов, а иногда и самой избирательной системы (Bogad, 2005). Возможности цифровых технологий позволяют проявляться коллективной гражданской позиции и религиозной идентичности. Такие жанры как видеоблоги и пародийные нарезки, являющиеся уникальными для цифровой 
визуальной культуры, становятся местом встречи создателей и их аудитории, способствуя формированию совместной позиции - «голоса». Указанные способы обращения к аудитории предполагают связь между рассредоточенными людьми, возникают новые формы «нераспределенной гражданственности» (Zoonen et al., 2010).

\section{Пародия в TikTok и методы (само)цензуры}

В качестве примера цифрового пространства рассмотрим платформу TikTok, с помощью которой можно распространять короткие видеоролики, обычно сопровождающиеся популярными песнями или другими саундтреками. С помощью данного сервиса пользователи в силах выпускать собственный контент, имитировать существующие видео-ролики других пользователей или пародировать популярные жанры, включая сам жанр TikTok (Mackenzie \& Nichols, 2020).

В период пандемии 2020 года TikTok пережил новый виток популярности. На платформе можно найти огромное количество примеров пародий на известных артистов, блогеров и даже животных. Содержание может включать сложные наслоения контекста: например, в одном и том же клипе музыкальное сопровождение намеренно неудачно повторяет мелодию из популярного фильма, видеоряд пародирует известный клип, а голос на фоне изображает автоматический переводчик. Кроме этого, сам жанр пародийных видео в TikTok возродил идею челленджей, которая порождает бесконечное число пародий на самих себя.

Пародийные видеоролики стали вирусными через механизмы рекомендаций в социальных сетях, появились новые микро-знаменитости - комикинепрофессионалы, которые выступают в качестве некой оппозиции к профессиональному юмористическому контенту. Пользователи используют средства пародии и импровизации как основу для контркультурного самовыражения, в частности, чтобы создавать карикатуры на существующие традиционные идеи, мифы и ценности (Ogbu, 2020).

Очевидно, что креативщики могут использовать средства массовой информации для повышения осведомленности о социальных и политических проблемах. Вопрос об уместности содержания и процесс принятия решения о содержании пародийных роликов зависят от собственных взглядов и конкретной позиции автора.

Так как пародия быстро распространяется через социальные сети, сложно обойти вниманием вопрос об этической модерации. Сами пользователи, которые создают контент и активно им пользуются, размышляют о компонентах цензуры на цифровых сервисах, таких как модерация и алгоритмическая фильтрация. Исследование пользовательских реакций на социальных платформах Tumblr и YouTube показывает, что модерация контента с помощью алгоритмов и новых условий использования сервисов влияет на культуру 
пользователей, вызывая сопротивление и ответную тактику адаптации к этим изменениям (Lamerichs, 2020). Несмотря на то, что правила нахождения в публичном пространстве сервисов доступны, алгоритмы рекомендаций и скрытия контента являются зачастую непрозрачными. Поэтому сами пользователи начинают создавать представления о механизмах их функционирования, подстраивая свой контент.

Рассмотрим пример блокировок пародийного контента, размещенного на социальном сервисе TikTok. Здесь цензуре могут подвергаться определенные хештеги - употребление уничижительных слов грозит блокировкой аккаунта или минимизацией показов другим пользователем (Mackenzie \& Nichols, 2020). Так, нейтральный, на первый взгляд, хэштег «геймер» был на некоторое время заблокирован после того, как его стали применять для размещения большого количества пародийных издевательств. Образ «девушки-геймера» использовался, чтобы эксплуатировать идею о «месте женщины на кухне», причем многие из этих шуток исходили от пользователей женского пола. Таким образом, высмеивание доминирующих общественных ценностей само стало напоминать форму издевательства, а пародия на другие пользовательские видео в TikTok оказалась рекурсивна по отношению к самой себе.

Другие инструменты, которые используются в сервисах для решения таких острых социальных проблем как травля и запугивание, включают в себя технологические решения, тесно завязанные на этических аспектах поступков людей. К таким решениям можно отнести автоматические алгоритмы, распознающие определенные сочетания слов, которые были отмечены как оскорбительные, и блокирующие подобные комментарии или аккаунты. Исследователи приходят к выводу, что по-настоящему этическим решением было бы создание мотивации к тому, чтобы сам пользователь принимал осознанное решение перед тем, как опубликует свой контент. Цензура алгоритмов не решает проблемы моральной автономии пользователя, пока средством убеждения служит вмешательство систем сервисов. Шаги в подобном направлении были сделаны сервисом Instagram, который ввел функцию всплывающего сообщения, где пользователю предлагается удалить свой комментарий прежде, чем он будет размещен, если он похож по содержанию на оскорбительный (Sullivan \& Reiner, 2020).

\section{Этические нормы и культурная травма в роликах TikTok}

Вне контекста политического или социального участия пародия может рассматриваться как средство преодоления неприятных ощущений от травмирующего события. Поскольку новости о конфликтах и насилии благодаря средствам массовой информации становятся составляющей частью жизни, в контексте культурной травмы люди используют цифровые медиа как пространство для их осмысления, а также определения способов реагирования на постоянную угрозу. В данном разделе приведены примеры подобного меха- 
низма сопротивления - комическое представление позволяет увидеть пережитое с другой, абсурдной или неэстетичной стороны. Этот механизм позволяет переключиться от убеждения в серьезности травмирующего события к убеждению в его заурядности. Так как данные ролики зачастую представляют собой жанр «горького смеха», они могут быть восприняты общественностью неоднозначно, как нечто оскорбляющее память о событии.

Понятие культурной травмы рассматривалось исследователями в контекстах географических границ и идентичности (Александер, 2012; Троицкий, 2017; Троицкий, 2019). Исследование Дж. Векери показало, как молодые люди проживают культурную травму с помощью игровых и меметических практик в социальных сетях (Vickery, 2020). В качестве материала были использованы видеоролики TikTok в жанре черного юмора, где мемефикации подверглись случаи стрельбы в американских школах. С помощью данных роликов молодые люди распространяли критические пародийные видео в ответ на политическое бездействие в отношении постоянной угрозы стрельбы. Данные ролики по содержанию были разделены на несколько групп:

1) высмеивание стереотипов и образов события в СМИ;

2) пародирование абсурдности насилия и реакции общественности;

3) театрализованное представление о насильственном действии.

Первая группа роликов воспроизводила или высмеивала стереотипы, которые были связаны с ситуацией. Эти сцены демонстрировали воображаемые способы защиты от конфликтов, например игру с образом стрелкаодиночки. Вторая группа видеороликов саркастически изображала символику, которую использовали власти и администрация в качестве борьбы с насилием, показывая несоответствие реальности и провозглашаемых ценностей. Третья группа видео с помощью художественных приемов в виде движений и танца воссоздавала декорации и сцену насилия, таким образом выражая то, что невозможно изобразить с помощью лингвистических средств.

Помимо этого, Дж. Векери систематизировал видеоролики в TickTok по использованию определенных меметических форм (повествование, музыка, визуальный монтаж) и функций (пародия, критика или утешение жертв насилия) (Vickery, 2020). Приведенные примеры явственно показывают, что меметическая, перфомативная природа пародийных видеороликов ищет различные способы взаимодействия с реальными событиями. Используются возможности собственного тела, культурный текст и технические ресурсы социальных платформ, чтобы в игровой форме препарировать общественные дискурсы и нормы, а в некоторых случаях и опровергать их.

Показательным примером служит широко известный общественный скандал, вызванный челленджем в TikTok - видеоблоггеры с нарисованными синяками и ранами под музыку от первого лица рассказывают истории о людях, которые стали жертвами концентрационных лагерей. Подобные теат- 
рализованные представления вызвали большие разногласия во мнениях. Одни нашли эти постановки оскорбляющими память погибших, осудили создателей роликов, другие восприняли их как образовательную акцию в память о трагедии (TikTok Creators Playing Dead Holocaust Victims Accused of Trauma - Insider). Таким образом, пародия становится важной формой современной саморефлексии в медиа, используя символический язык и имитацию (или неправильное цитирование) источника (Palmer, 2005).

Пародийные видеоролики в иррациональной форме демонстрируют реакции на поколенческие трагедии, которые существуют и структурируют пространство молодых людей в рамках более широких общественных дискурсов. Происходит идентификация себя с пострадавшей стороной (как сопричастных), а сама меморизация событий осуществляется с использованием шаблонов повторения и подражания. Таким образом, пародия может служить средством выражения культурной травмы, а намеренно абсурдное представление событий является механизмом защиты. Социальные возможности TikTok позволяют в игровой форме коллективно осмыслить это, заново пересобрать существующие ценности и определить отношение к ним.

\section{Заключение}

С появлением новых форм трансляции пародии, таких как короткие видеоролики, по-прежнему остаются открытыми важные вопросы: какие темы или трактовки можно считать приемлемыми, а какие оскорбительными? Есть ли составляющие современной общественной или личной жизни, которые являются запретными для шуток? Как поступать с оскорбительным юмором в социальных сетях? Кроме того, неясно, до какой степени пародия обязана быть смешной и до какой степени - критической.

В статье пародия была рассмотрена как явление, устанавливающее и укрепляющее социальные связи, скорость образования которых особенно заметна с появлением социальных сервисов и возможностью делиться критическими комментариями с мировой аудиторией. На примерах коротких пародийных видеороликов в TikTok показано, как изначальный смысл дестабилизируется через аллюзию на реальные события и существовавших людей. Игровая, непрактичная ориентация этих представлений занимает центральное место, а сами видеоролики не всегда создаются с целью рассмешить аудиторию. С помощью дополнительных смыслов пародия может изменить восприятие оригинала зрителями, а ключевым этическим вопросом является уместность такого переиначивания. Моральная оценка обычно концентрируется на практических последствиях, тогда как комическое далеко не всегда практично, ведь в большинстве случаев оно служит ради удовольствия, а не для того, чтобы передать точную информацию. Это свойство пародии затрудняет ее этическое истолкование. 
Наконец, мы рассмотрели некоторые составляющие цензуры пародийных видео в социальных сервисах. Запреты подобного рода как часть системы управления информацией вызывают еще больший комический ответ, приводят к тому, что пользователи адаптируют свой контент под ограничения или находят способы их обхождения.

\section{Благодарности}

Исследование выполнено в рамках гранта РФФИ No18-011-00673А «Методология этической экспертизы».

The research was supported by Russian Foundation for Basic Research (Project No. 18-011-00673A "Methodology of ethical expertise")

\section{Список литературы}

Ankel, S. (2020). TikTok creators are pretending to be Holocaust victims in heaven in a new trend dubbed 'trauma porn'. Retrieved from https://www.insider.com/tiktok-trend-shows-peoplepretending-to-be-holocaust-victims-heaven-2020-8

Becker, A. \& Waisanen, D. (2013). From Funny Features to Entertaining Effects: Connecting Approaches to Communication Research on Political Comedy. Review of Communication, 13 (3), 161-183. doi: 10.1080/15358593.2013.826816

Benatar, D. (1999). Prejudice in Jest: When Racial and Gender Humor Harms. Public Affairs Quarterly, 13 (2), 191-203.

Bogad, L. M. (2005). Electoral Guerrilla Theatre: Radical Ridicule and Social Movements. London: Routledge. doi: 10.4324/9780203401033

D'Errico, F. \& Poggi, I. (2016). “The Bitter Laughter". When Parody Is a Moral and Affective Priming in Political Persuasion. Frontiers in Psychology, 7 (1144). doi: 10.3389/fpsyg.2016.01144

Guo, M. (2018). Playfulness, parody, and carnival: Catchphrases and mood on the Chinese Internet from 2003 to 2015. Communication and the Public, 3 (2), 134-150. doi: $10.1177 / 2057047318770467$

Hariman, R. (2008). Political Parody and Public Culture. Quarterly Journal of Speech, 94 (3), 247-272. doi: 10.1080/00335630802210369

Harvey, J. (1995). Humor as social act: Ethical issues. The Journal of Value Inquiry, 29 (1), 19-30. doi: 10.1007/BF01079060

Hmielowski, J. D., Holbert, R. L. \& Lee, J. (2011). Predicting the Consumption of Political TV Satire: Affinity for Political Humor, The Daily Show, and The Colbert Report. Communication Monographs, 78 (1), 96-114. doi: 10.1080/03637751.2010.542579

Hoffman, L. H. \& Young, D. G. (2011). Satire, Punch Lines, and the Nightly News: Untangling Media Effects on Political Participation. Communication Research Reports, 28 (2), 159-168. doi: 10.1080/08824096.2011.565278

Holbert, R. L. (2020). Entertainment media and politics: Advances in effects-based research. London; New York: Routledge. 
Jones, M. O. (2017). Satire, social media and revolutionary cultural production in the Bahrain uprising: From utopian fiction to political satire. Communication and the Public, 2 (2), 136-153. doi: $10.1177 / 2057047317706372$

LaFollette, H. \& Shanks, N. (1993). Belief and the Basis of Humor. American Philosophical Quarterly, 30 (4), 329-339.

Lamerichs, N. (2020). User Tactics and Algorithms: A Digital Humanities Approach to YouTube and Tumblr. In D. Nguyen, I. Dekker \& S. Nguyen (Eds.), Understanding Media and Society in the Age of Digitalisation (pp. 35-54). Cham: Springer International Publishing. Doi: 10.1007/978-3-030-38577-4_3

Lim, J. S. \& Golan, G. J. (2011). Social Media Activism in Response to the Influence of Political Parody Videos on YouTube. Communication Research, 38 (5), 710-727. doi: 10.1177/0093650211405649

Lockyer, Sh. \& Pickering, M. (2005). Introduction: The Ethics and Aesthetics of Humour and Comedy. In S. Lockyer \& M. Pickering (Eds.), Beyond a Joke: The Limits of Humour (pp. 1-24). London: Palgrave Macmillan UK. doi: 10.1057/9780230236776_1

Mackenzie, S. A. \& Nichols, D. (2020). Finding 'Places to Be Bad' in Social Media: The Case of TikTok. In D. Nichols \& S. Perillo (Eds.), Urban Australia and Post-Punk: Exploring Dogs in Space (pp. 285-298). Singapore: Springer Singapore. doi: 10.1007/978-981-32-9702-9_22

Morreall, J. (2005). Humour and the Conduct of Politics. In Sh. Lockyer \& M. Pickering (Eds.), Beyond a Joke: The Limits of Humour (pp. 63-78). London: Palgrave Macmillan UK. doi: 10.1057/9780230236776_4

Nabi, R. L., Moyer-Gusé, E. \& Byrne, S. (2007). All Joking Aside: A Serious Investigation into the Persuasive Effect of Funny Social Issue Messages. Communication Monographs, 74 (1), 29-54. doi: 10.1080/03637750701196896

Ogbu, O. G. (2020). "She completely twisted the body language": Pandemic, parody, politics, and comedy in the era of coronavirus. Journal of Community Safety and Well-Being, 5 (2), 82-86. doi: $10.35502 /$ jcswb.138

Palmer, J. (2005). Parody and Decorum: Permission to Mock. In Sh. Lockyer \& M. Pickering (Eds.), Beyond a Joke: The Limits of Humour (pp. 79-97). London: Palgrave Macmillan UK. Doi: 10.1057/9780230236776_5

Peifer, J. T. (2012). Can We Be Funny? The Social Responsibility of Political Humor. Journal of Mass Media Ethics, 27 (4), 263-276. doi: 10.1080/08900523.2012.746110

Petrović, T. (2018). Political Parody and the Politics of Ambivalence. Annual Review of Anthropology, 47 (1), 201-216. doi: 10.1146/annurev-anthro-102215-100148

Piata, A. (2016). When metaphor becomes a joke: Metaphor journeys from political ads to internet memes. Journal of Pragmatics, 106, 39-56. doi: 10.1016/j.pragma.2016.10.003

Ruliou, A. (2015). Political Internet Memes as User-generated Political Caricatures and Means of Reaction to Propaganda: The Case of Rushka Kvadratnyi Vatnik (MA Thesis). Warsawa.

Shuster, M. (2013). Humor as an Optics: Bergson and the Ethics of Humor. Hypatia, 28 (3), 618-632. doi: 10.1111/j.1527-2001.2012.01282.x

Smuts, A. (2010). The Ethics of Humor: Can Your Sense of Humor be Wrong? Ethical Theory and Moral Practice, 13 (3), 333-347. doi: 10.1007/s10677-009-9203-5

Sullivan, L. S. \& Reiner, P. B. (2020). Ethics in the Digital Era: Nothing New? IT Professional, 22 (1), 39-42. doi: 10.1109/MITP.2020.2964355 
Tapley, R. (2007). The Value of Humor. The Journal of Value Inquiry, 40 (4), 421-431. doi: 10.1007/s10790006-9007-y

van Zoonen, L., Vis, F. \& Mihelj, S. (2010). Performing citizenship on YouTube: Activism, satire and online debate around the anti-Islam video Fitna. Critical Discourse Studies, 7 (4), 249-262. doi: 10.1080/17405904.2010.511831

Vickery, J. R. (2020). The Memeification of \#Schoolshootings in the U.S.: Youth, Tiktok, and Playful Mediated Bodies. In AoIR Selected Papers of Internet Research. Retrieved from https://spir.aoir.org/ojs/index.php/spir/article/view/11357

Александер, Д. (2012). Культурная травма и коллективная идентичность. Социологический журнал, (3), 5-40.

Троицкий, С. А. (2017). Синтксис утраты. Studia Culturae, (32), 160-172.

Троицкий, С. А. (2019). Конструкт травмы как основа для формирования топографической иерархии. Неприкосновенный запас. Дебаты о политике и культуре, 123 (1), 123-131.

\section{References}

Alexander, D. (2012). Cultural trauma and collective identity. Sociological journal, (3), 5-40. (In Russian).

Ankel, S. (2020). TikTok creators are pretending to be Holocaust victims in heaven in a new trend dubbed 'trauma porn'. Retrieved from https://www.insider.com/tiktok-trend-shows-peoplepretending-to-be-holocaust-victims-heaven-2020-8

Becker, A. \& Waisanen, D. (2013). From Funny Features to Entertaining Effects: Connecting Approaches to Communication Research on Political Comedy. Review of Communication, 13 (3), 161-183. doi: 10.1080/15358593.2013.826816

Benatar, D. (1999). Prejudice in Jest: When Racial and Gender Humor Harms. Public Affairs Quarterly, 13(2), 191-203.

Bogad, L. M. (2005). Electoral Guerrilla Theatre: Radical Ridicule and Social Movements. London: Routledge. doi: 10.4324/9780203401033

D’Errico, F. \& Poggi, I. (2016). The Bitter Laughter". When Parody Is a Moral and Affective Priming in Political Persuasion. Frontiers in Psychology, 7 (1144). doi: 10.3389/fpsyg.2016.01144

Guo, M. (2018). Playfulness, parody, and carnival: Catchphrases and mood on the Chinese Internet from 2003 to 2015. Communication and the Public, 3 (2), 134-150. doi: $10.1177 / 2057047318770467$

Hariman, R. (2008). Political Parody and Public Culture. Quarterly Journal of Speech, 94 (3), 247-272. doi: 10.1080/00335630802210369

Harvey, J. (1995). Humor as social act: Ethical issues. The Journal of Value Inquiry, 29 (1), 19-30. doi: 10.1007/BF01079060

Hmielowski, J. D., Holbert, R. L. \& Lee, J. (2011). Predicting the Consumption of Political TV Satire: Affinity for Political Humor, The Daily Show, and The Colbert Report. Communication Monographs, 78 (1), 96-114. doi: 10.1080/03637751.2010.542579

Hoffman, L. H. \& Young, D. G. (2011). Satire, Punch Lines, and the Nightly News: Untangling Media Effects on Political Participation. Communication Research Reports, 28 (2), 159-168. doi: 10.1080/08824096.2011.565278 
Holbert, R. L. (2020). Entertainment media and politics: Advances in effects-based research. London; New York: Routledge.

Jones, M. O. (2017). Satire, social media and revolutionary cultural production in the Bahrain uprising: From utopian fiction to political satire. Communication and the Public, 2 (2), 136-153. doi: 10.1177/2057047317706372

LaFollette, H. \& Shanks, N. (1993). Belief and the Basis of Humor. American Philosophical Quarterly, 30 (4), 329-339.

Lamerichs, N. (2020). User Tactics and Algorithms: A Digital Humanities Approach to YouTube and Tumblr. In D. Nguyen, I. Dekker \& S. Nguyen (Eds.), Understanding Media and Society in the Age of Digitalisation (pp. 35-54). Cham: Springer International Publishing. Doi: 10.1007/978-3-030-38577-4_3

Lim, J. S. \& Golan, G. J. (2011). Social Media Activism in Response to the Influence of Political Parody Videos on YouTube. Communication Research, 38 (5), 710-727. doi: 10.1177/0093650211405649

Lockyer, Sh. \& Pickering, M. (2005). Introduction: The Ethics and Aesthetics of Humour and Comedy. In S. Lockyer \& M. Pickering (Eds.), Beyond a Joke: The Limits of Humour (pp. 1-24). London: Palgrave Macmillan UK. doi: 10.1057/9780230236776_1

Mackenzie, S. A. \& Nichols, D. (2020). Finding 'Places to Be Bad' in Social Media: The Case of TikTok. In D. Nichols \& S. Perillo (Eds.), Urban Australia and Post-Punk: Exploring Dogs in Space (pp. 285-298). Singapore: Springer Singapore. doi: 10.1007/978-981-32-9702-9_22

Morreall, J. (2005). Humour and the Conduct of Politics. In Sh. Lockyer \& M. Pickering (Eds.), Beyond a Joke: The Limits of Humour (pp. 63-78). London: Palgrave Macmillan UK. doi: 10.1057/9780230236776_4

Nabi, R. L., Moyer-Gusé, E. \& Byrne, S. (2007). All Joking Aside: A Serious Investigation into the Persuasive Effect of Funny Social Issue Messages. Communication Monographs, 74 (1), 29-54. doi: 10.1080/03637750701196896

Ogbu, O. G. (2020). "She completely twisted the body language": Pandemic, parody, politics, and comedy in the era of coronavirus. Journal of Community Safety and Well-Being, 5 (2), 82-86. doi: $10.35502 /$ jcswb.138

Palmer, J. (2005). Parody and Decorum: Permission to Mock. In Sh. Lockyer \& M. Pickering (Eds.), Beyond a Joke: The Limits of Humour (pp. 79-97). London: Palgrave Macmillan UK. Doi: 10.1057/9780230236776_5

Peifer, J. T. (2012). Can We Be Funny? The Social Responsibility of Political Humor. Journal of Mass Media Ethics, 27 (4), 263-276. doi: 10.1080/08900523.2012.746110

Petrović, T. (2018). Political Parody and the Politics of Ambivalence. Annual Review of Anthropology, 47 (1), 201-216. doi: 10.1146/annurev-anthro-102215-100148

Piata, A. (2016). When metaphor becomes a joke: Metaphor journeys from political ads to internet memes. Journal of Pragmatics, 106, 39-56. doi: 10.1016/j.pragma.2016.10.003

Ruliou, A. (2015). Political Internet Memes as User-generated Political Caricatures and Means of Reaction to Propaganda: The Case of Rushka Kvadratnyi Vatnik (MA Thesis). Warsawa.

Shuster, M. (2013). Humor as an Optics: Bergson and the Ethics of Humor. Hypatia, 28 (3), 618-632. doi: 10.1111/j.1527-2001.2012.01282.x

Smuts, A. (2010). The Ethics of Humor: Can Your Sense of Humor be Wrong? Ethical Theory and Moral Practice, 13 (3), 333-347. doi: 10.1007/s10677-009-9203-5 
Sullivan, L. S. \& Reiner, P. B. (2020). Ethics in the Digital Era: Nothing New? IT Professional, 22 (1), 39-42. doi: 10.1109/MITP.2020.2964355

Tapley, R. (2007). The Value of Humor. The Journal of Value Inquiry, 40 (4), 421-431. doi: 10.1007/s10790006-9007-y

Troitsky, S. A. (2017). The Syntax for Loss. Studia Culturae, (32), 160-172. (In Russian).

Troitsky, S. A. (2019). Trauma construct as a basis for the formation of a topographic. The untouchable reserve. Debate about politics and culture, 123 (1), 123-131.(In Russian).

van Zoonen, L., Vis, F. \& Mihelj, S. (2010). Performing citizenship on YouTube: Activism, satire and online debate around the anti-Islam video Fitna. Critical Discourse Studies, 7 (4), 249-262. doi: 10.1080/17405904.2010.511831

Vickery, J. R. (2020). The Memeification of \#Schoolshootings in the U.S.: Youth, Tiktok, and Playful Mediated Bodies. In AoIR Selected Papers of Internet Research. Retrieved from https://spir.aoir.org/ojs/index.php/spir/article/view/11357 